\title{
Ventilation and fire door coverage solution at the Chuquicamata underground mine project
}

\author{
RA Álvarez Codelco, Chile \\ El Acuña Universidad del Desarrollo, Chile
}

\begin{abstract}
Chuquicamata open pit mine, one of the largest in the world, is transitioning to become one of the largest underground copper mines, comparable to El Teniente mine. Currently, surface production is diminishing and systems are being installed for the underground operation; in particular the ventilation infrastructure that will support most of the development for the upcoming years. The Chuquicamata underground mine project has considered different construction packages for the development which require a number of fans and doors to achieve the required airflow distribution. As part of the detailed engineering phase, an updated study of the type of doors, number, location, and commissioning schedule was developed. This paper presents the ventilation door coverage solution proposed as an update of the previous engineering phase to validate the door commissioning timelines and initial cost estimation. A comparison is made between the initial and the updated scope of doors in terms of types, quantity, cost, and timelines according to the latest construction plan. A discussion of the results obtained is presented, followed by a recommendation.
\end{abstract}

Keywords: underground doors schedule, ventilation doors, fire doors

\section{Introduction}

The Chuquicamata underground mine project (PMCHS) is currently under development in the north of Chile, and will ramp up to a production rate of $140,000 \mathrm{tpd}$. The main product is copper and it is estimated that the mine will be producing at full capacity by the end of 2021. The development of this new underground mine has opened a unique window for the personnel involved in the project to consider adopting the latest technology available in terms of ventilation and fire doors. At the same time, it provides the opportunity to build a business case for adopting new types of doors according to what is now available on the market and the updated requirements.

In the previous phase of engineering, the number of doors and their locations was estimated based on the information available at the time, but it was not possible to define which type of door would better suit the requirements of each potential location. As a result, a single type of door was selected for the location with the most demanding requirements, and then used for all other door locations. This allowed the previous engineering phase to reach a solution that accounted for all technical and economical requirements. Unfortunately, as a result of the strategy used, the selected door was expensive and so was the overall solution; however, it provided an important opportunity for improvement in the next engineering phase. The unique door solution was accounted for in the project budget, with the commitment to review the solution in the current phase of engineering as more information became available.

This paper presents the initial condition, in terms of the information available in the previous phase of engineering, and the details of the solution proposed. Furthermore, the reviewed solution is presented considering the information available in the current phase of engineering, both for the project and for the commercially available technology. Finally, a discussion of the results is presented and the recommendation for the project implementation is included. 


\section{Previous engineering phase solution}

The construction phase considered 37 ventilation doors and 10 fire doors, PVE and PCI respectively (from the Spanish terms for ventilation door and fire door), to be installed between 2015 and 2018, totalling 47 doors. Fire doors are commonly related to emergency plans, fuel bays, explosive storage, electrical stations, and others. Ventilation doors are used to establish the airflow distribution circuits required to meet the development and production plan (McPherson 2009). Figure 1 presents an example of the distribution layout of 15 ventilation and six fire doors for the infrastructure levels. The remaining ventilation doors and fire doors are distributed among the undercut (UCL), production (PROD), ventilation (VENT), and haulage (NT) levels, and are also located in the conveyor and access tunnels.

The early installation of these doors during the construction phase was expected to help establish the ventilation circuits that could enable contractors to work underground in certain areas supported by assigned fresh air circuits, while blasting occurred in other defined areas, given that ventilation doors were in place and the main fans were operating. This would allow for better use of the mining resources throughout the shifts and potentially deliver a higher development rate.

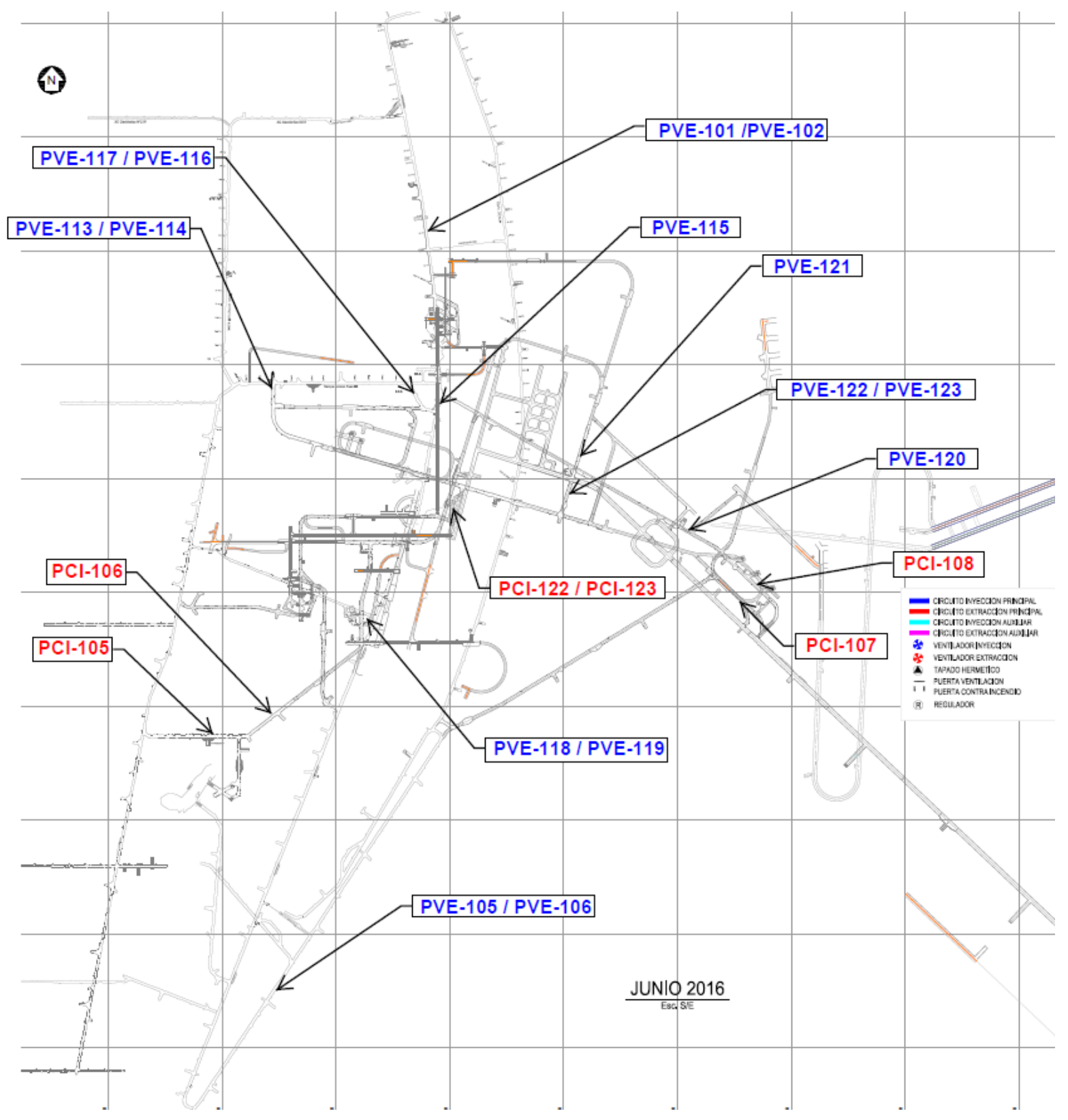

Figure 1 Ventilation and fire door layout example 
As previously mentioned, in the initial ventilation system design, two types of doors were considered with fundamentally different concepts, to meet two different purposes. The first type is the ventilation door commonly referred to as airlocks. These doors are usually installed in series, one after the other, in the same drift, and are expected to always be closed, except when a vehicle is passing through. In order to preserve the airlock, two or three doors are usually mounted in series and are equipped with an interlock that allows for only one door to be opened at a time, preventing any other door from opening before they are all closed. The ventilation door usually includes a small access door for pedestrians, which has to be manually opened and closed.

The second type is the fire door, which is expected to always be open, except in the event of an emergency such as an underground fire, which requires closing a certain number of fire doors according to the fire location, the exit strategy for workers, and containment/removal strategy for fire fumes. Exceptionally, in the case of a fire, ventilation doors can be opened as part of the emergency strategy for workers or fumes to exit. The plan is to have all ventilation and fire doors working remotely from a central or remote control room which would allow for their manual control and use in case of a fire.

Clear definitions and requirements for ventilation and fire doors need to be met before purchasing or installing a new door. Mine standards require that ventilation doors have to be coated with a pattern of black and yellow paint, while fire doors have to be coated with a pattern of red and yellow paint. The materials and the paint used for fire doors needs to be fire proof, meeting the current Standard for Emergency and Standby Power Systems (National Fire Protection Association 2016). The colour difference makes it easier for personnel to differentiate which door has to be open and which door has to be closed. This is particularly beneficial in the case of identifying a malfunction or power loss.

In 2017 and 2018 the operation focused mainly on the mine development and facility construction to enable operations to begin in 2019. Several different types of equipment will be required to pass through the ventilation and fire doors during the construction phase such as mining trucks, drills, scoops (LHDs), front loaders, shotcrete trucks, supply trucks, and scissor lifts, among others. For the production requirement, it was identified that the tallest equipment required to pass through a door is the mining truck (Dumper Doosan 40 Tons) with a $3.85 \mathrm{~m}$ height, as presented in Figure 2. After considering the clearance tolerance, the minimum specifications for ventilation and fire doors in the production areas of the PMCHS was established at $4.5 \mathrm{~m}$ high and $4.5 \mathrm{~m}$ wide.

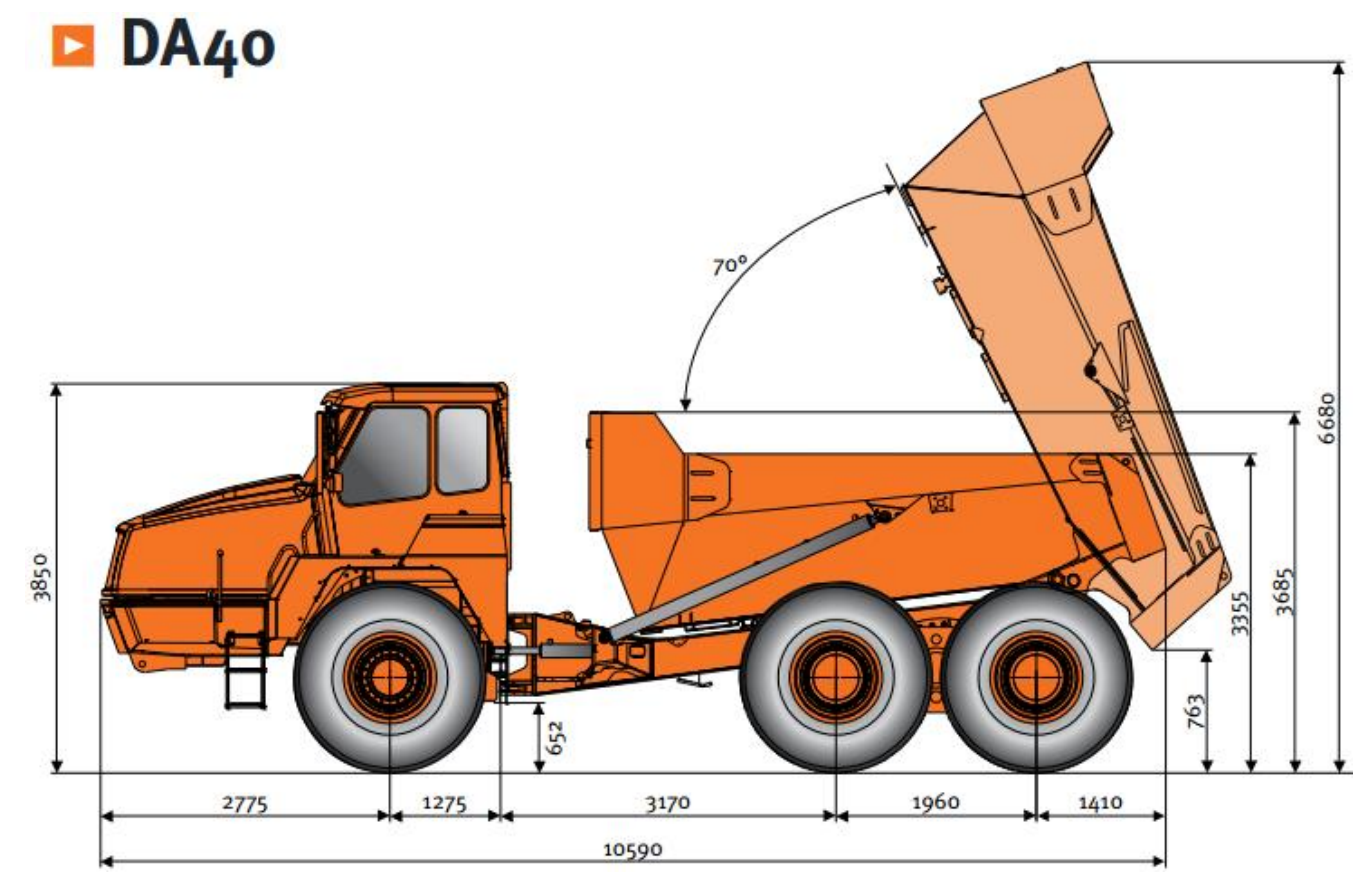

Figure 2 Mining truck dimensions 
The assembly of the final infrastructure, including the main ventilation fans, ventilation and fire doors, regulators, stoppings, crushers, conveyor belts, concrete plants, fuel bays and ore transfer stations, is part of the current construction plan. The parts required to assemble the mine infrastructure also need to be considered before finalising the door widths and heights. It was decided that two different door sizes would be required to accommodate the production and infrastructure needs. For the infrastructure requirements, it was identified that the largest infrastructure to pass through a door after considering clearance would require a $6.5 \mathrm{~m}$ height and $6.5 \mathrm{~m}$ width. As a result, the two main door section requirements were defined: $4.5 \times 4.5 \mathrm{~m}$ and $6.5 \times 6.5 \mathrm{~m}$.

Table 1 presents the summary of the 47 ventilation and fire doors, considering the initial estimate for pressure drop requirements and dimensions.

Table 1 Ventilation and fire doors summary

\begin{tabular}{llll}
\hline Door type & Number of doors & Dimensions $(\mathrm{m})$ & Estimated pressure drop \\
\hline Ventilation size A & 25 & $4.5 \times 4.5$ & $2,500 \mathrm{~Pa}(10 \mathrm{in} . \mathrm{wg})$ \\
Ventilation size B & 12 & $6.5 \times 6.5$ & $2,500 \mathrm{~Pa}(10 \mathrm{in} . \mathrm{wg})$ \\
Fire size A & 6 & $4.5 \times 4.5$ & $2,500 \mathrm{~Pa}(10 \mathrm{in} . \mathrm{wg})$ \\
Fire size B & 4 & $6.5 \times 6.5$ & $2,500 \mathrm{~Pa}(10 \mathrm{in} . \mathrm{wg})$ \\
\hline
\end{tabular}

Note: in. wg = inches of water gauge.

The most common type of ventilation and fire doors used in underground mines in Chile are known as barn doors. These have two panels opening from the centre of the door to the sides, pivoting on the outside vertical edge of the panel as located in the frame that supports the doors. Doors of this type must be opened in the opposite direction of the expected airflow, mainly for safety reasons, to avoid the possibility of an abrupt opening and the potential for personal injury or mine equipment damage. Figure 3 presents the barn door.

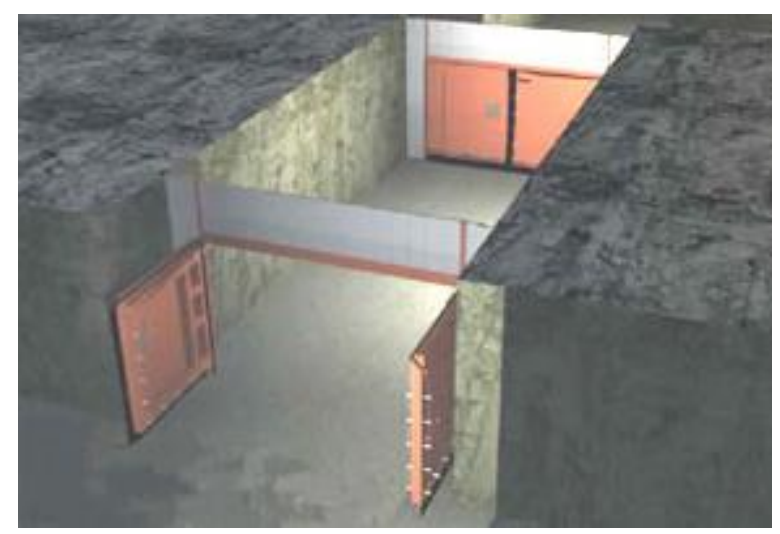

\section{Figure 3 Barn door}

Codelco has extensive experience at their Chilean mine sites in the use of this kind of ventilation and fire door, as they have historically been used in all of their underground mines. 
Table 2 presents the updated cost estimate, which considers supply, installation, and maintenance for one year.

Table 2 Ventilation and fire door costs summary for barn type door

\begin{tabular}{llllll}
\hline Door type & $\begin{array}{l}\text { Number } \\
\text { of doors }\end{array}$ & $\begin{array}{l}\text { Unit supply } \\
\text { cost (USD) }\end{array}$ & $\begin{array}{l}\text { Unit install } \\
\text { cost (USD) }\end{array}$ & $\begin{array}{l}\text { Unit yearly } \\
\text { maintenance cost (USD) }\end{array}$ & $\begin{array}{l}\text { Total cost } \\
\text { (USD) }\end{array}$ \\
\hline Ventilation size A & 25 & 51,775 & 39,413 & 10,051 & $2,530,975$ \\
Ventilation size B & 12 & 67,307 & 51,237 & 10,051 & $1,543,140$ \\
Fire size A & 6 & 59,592 & 39,413 & 10,051 & 654,336 \\
Fire size B & 4 & 77,470 & 51,237 & 10,051 & 555,032 \\
Total & 47 & $2,769,491$ & $2,041,595$ & 472,397 & $5,283,483$ \\
\hline
\end{tabular}

To date, of the 37 ventilation doors in the list, 11 (30\%) have been installed, in accordance with the initial plan.

\section{Updated engineering solution}

\subsection{Plan update}

The previous engineering phase for the Chuquicamata underground project considered the installation of 100 doors when the mine became operational, including both ventilation and fire doors. The current construction phase only considers a total of 47 doors out of the initial 100 , including both ventilation and fire doors. The first 47 ventilation and fire doors from the previous engineering phase did not experience location changes through the current engineering revision.

The remaining 53 doors, part of the next construction phase, are currently undergoing a budget optimisation review study which is being developed in an effort to reduce the capital expenditure within the economic challenges facing the copper industry. As a result of the current review, the location and quantity of the remaining doors still needs to be validated.

As part of the scope of work of the current development contractor, 21 doors have to be purchased, installed and maintained during 2017. The remaining 26 doors required by 2019 are to be part of another scope of work that will be assigned by July 2017. The final decision of how many of the 26 barn doors will be switched to a new style door is still under review.

\subsection{Criteria and door revision}

Initially, ventilation and fire doors were required to withstand a 2,500 Pa (10 in. wg) pressure differential irrespective of their mine location. This design requirement resulted in two alternatives; either the use of doors in series distributing pressure drop between two or three doors, or the installation of one heavy duty door. The heavy duty door design was more robust but needed additional development and more complex systems to operate. The single robust door solution also meant a higher purchasing cost for the project as determined by the early engineering. As indicated previously, from an airflow distribution perspective, multiple ventilation or fire doors that allow for the possibility to generate an airlock are preferable to a single door that cannot generate an airlock. Based on the airlock consideration and recognising the use of multiple doors in series, new pressure drop requirements were defined and are presented in Table 3. 
Table 3 Ventilation and fire doors (47) summary update

\begin{tabular}{|c|c|c|c|c|c|c|c|}
\hline Door & $\begin{array}{l}\text { Pressure } \\
\text { drop } \\
\text { estimate } \\
\text { (Pa; in. wg) }\end{array}$ & $\begin{array}{l}\text { Measured } \\
\text { pressure } \\
\text { drop } \\
\text { (Pa; in. wg) }\end{array}$ & $\begin{array}{l}\text { Dimensions } \\
\text { (m) }\end{array}$ & Door & $\begin{array}{l}\text { Pressure } \\
\text { drop } \\
\text { estimate } \\
\text { (Pa; in. wg) }\end{array}$ & $\begin{array}{l}\text { Measured } \\
\text { pressure } \\
\text { drop } \\
\text { (Pa; in. wg) }\end{array}$ & $\begin{array}{l}\text { Dimensions } \\
\text { (m) }\end{array}$ \\
\hline PVE-101 & 2,$500 ; 10$ & 2,$000 ; 8$ & $4.5 \times 4.5$ & PVE INY-01 & 1,250; 5 & - & $4.5 \times 4.5$ \\
\hline PVE-102 & 2,$500 ; 10$ & 2,$000 ; 8$ & $4.5 \times 4.5$ & PVE INY-02 & 1,$250 ; 5$ & - & $4.5 \times 4.5$ \\
\hline PVE-105 & 1,$250 ; 5$ & $75 ; 0.3^{*}$ & $4.5 \times 4.5$ & PVE INY-03 & 1,250; 5 & - & $4.5 \times 4.5$ \\
\hline PVE-106 & 1,250; 5 & $75 ; 0.3^{*}$ & $4.5 \times 4.5$ & PVE INY-04 & 1,$250 ; 5$ & - & $6.5 \times 6.5$ \\
\hline PVE-113 & 1,$250 ; 5$ & $50 ; 0.2$ & $4.5 \times 4.5$ & PVE INY-05 & 1,250; 5 & - & $6.5 \times 6.5$ \\
\hline PVE-114 & 1,$250 ; 5$ & $50 ; 0.2$ & $4.5 \times 4.5$ & PVE INY-06 & 1,$250 ; 5$ & - & $6.5 \times 6.5$ \\
\hline PVE-115 & 1,250; 5 & $75 ; 0.3$ & $4.5 \times 4.5$ & PVE INY-07 & 1,$250 ; 5$ & - & $6.5 \times 6.5$ \\
\hline PVE-116 & 1,250; 5 & $75 ; 0.3$ & $4.5 \times 4.5$ & PVE INY-08 & 1,250; 5 & - & $6.5 \times 6.5$ \\
\hline PVE-117 & 1,$250 ; 5$ & $75 ; 0.3$ & $4.5 \times 4.5$ & PVE INY-09 & 1,$250 ; 5$ & - & $6.5 \times 6.5$ \\
\hline PVE-118 & 2,$500 ; 10$ & $75 ; 0.3$ & $4.5 \times 4.5$ & PVE INY-10 & 1,$250 ; 5$ & - & $6.5 \times 6.5$ \\
\hline PVE-119 & 2,$500 ; 10$ & $75 ; 0.3$ & $4.5 \times 4.5$ & PVE INY-11 & 1,$250 ; 5$ & - & $6.5 \times 6.5$ \\
\hline PVE-120 & 1,$250 ; 5$ & $100 ; 0.4^{*}$ & $4.5 \times 4.5$ & PVE INY-12 & 1,$250 ; 5$ & - & $6.5 \times 6.5$ \\
\hline PVE-121 & 1,$250 ; 5$ & $100 ; 0.4^{*}$ & $4.5 \times 4.5$ & PVE INY-13 & 1,$250 ; 5$ & - & $6.5 \times 6.5$ \\
\hline PVE-122 & 2,$500 ; 10$ & $300 ; 1.2$ & $4.5 \times 4.5$ & PCl-105 & 1,$250 ; 5$ & - & $4.5 \times 4.5$ \\
\hline PVE-123 & 2,$500 ; 10$ & $300 ; 1.2$ & $4.5 \times 4.5$ & PCl-106 & 1,$250 ; 5$ & - & $4.5 \times 4.5$ \\
\hline PVE TA-01 & 1,$250 ; 5$ & - & $4.5 \times 4.5$ & PCl-107 & 1,$250 ; 5$ & - & $4.5 \times 4.5$ \\
\hline PVE TA-02 & 1,$250 ; 5$ & - & $4.5 \times 4.5$ & PCl-108 & 1,$250 ; 5$ & - & $4.5 \times 4.5$ \\
\hline PVE TA-03 & 1,$250 ; 5$ & - & $4.5 \times 4.5$ & $\mathrm{PCl}-122$ & 1,250; 5 & - & $4.5 \times 4.5$ \\
\hline PVE TA-04 & 1,$250 ; 5$ & - & $4.5 \times 4.5$ & $\mathrm{PCl}-123$ & 1,$250 ; 5$ & - & $4.5 \times 4.5$ \\
\hline PVE TA-05 & 1,$250 ; 5$ & - & $6.5 \times 6.5$ & PCI TA-01 & 1,$250 ; 5$ & - & $6.5 \times 6.5$ \\
\hline PVE TA-06 & 1,$250 ; 5$ & - & $6.5 \times 6.5$ & PCI TA-02 & 1,$250 ; 5$ & - & $6.5 \times 6.5$ \\
\hline PVE TA-07 & 1,$250 ; 5$ & - & $4.5 \times 4.5$ & PCI TA-03 & 1,$250 ; 5$ & - & $6.5 \times 6.5$ \\
\hline PVE TA-08 & 1,250; 5 & - & $4.5 \times 4.5$ & PCI TA-04 & 1,250; 5 & - & $6.5 \times 6.5$ \\
\hline PVE TA-09 & 1,$250 ; 5$ & - & $4.5 \times 4.5$ & - & - & - & - \\
\hline
\end{tabular}

*Value not yet measured.

In Table 3, only six ventilation doors remained at 2,500 Pa (10 in. wg). For two of the six 2,500 Pa (10 in. wg) installed doors, the pressure drop was measured at 2,000 Pa (8 in. wg). For the other four, two were at $75 \mathrm{~Pa}$ (0.3 in. wg) and two at $300 \mathrm{~Pa}$ (1.2 in. wg). For the rest of the doors, the pressure drops were modified to $1,250 \mathrm{~Pa}(5 \mathrm{in} . \mathrm{wg})$, and for the remaining doors already in place, the pressure drop measurements ranged from $300 \mathrm{~Pa}$ (1.2 in. wg) to $50 \mathrm{~Pa}$ (0.2 in. wg). The pressure drop across the doors is expected to rise closer to the design as the ventilation plan is implemented. In Table 3, the measured pressure drop values with an asterisk indicate that the value is not yet measured, but expected as per the updated ventilation simulation. 
Furthermore, as the mine expands, the ventilation plan has to change accordingly, impacting the airflow distribution, and resulting in some ventilation circuits changing completely. For example, some intake shafts are converted into exhaust shafts or vice versa, or simply closed because they are no longer useful for the project. It is expected that future ventilation and fire doors (some of the remaining 53) will need to be relocated, removed, or their opening orientation reversed according to changes in the airflow direction of the ventilation system at specific times in the project schedule. It has been identified in the ventilation plan that some of the current construction phase doors (47) will require similar changes in the near future.

Ventilation circuits are expected to change every eight months during the construction phase. The impact of stopping current development or potentially production when a door needed to be reversed due to airflow direction change was identified as a high risk to the committed schedule. A door change was estimated to take two weeks per door with a significant disruption of the airflow distribution. On the other hand, leaving the door installed in the wrong direction had a significant potential for personal injury and equipment damage. As such, the development plan required a functional ventilation and fire door that would not need to be reversed due to airflow distribution changes.

Additionally, and taking into account the work force acceptance component, a door with a similar design to the well-known, and used in other Codelco mine sites, barn doors would be better received by workers, in particular, if its operation also had the advantage of being independent of the airflow orientation.

Based on the previous reasons, the barn door type considered in the previous phase of engineering had to be assessed on a door location basis, according to the ventilation plan. Three alternative replacement solutions were identified as being readily available on the market and already proven in other mine sites: roll over, roll up and swing doors. A fourth alternative was identified, named bi-fold overhead door, but with no proven underground use.

The roll over door consists of several hinged steel sections that are mounted one on top of the other and are guided to a horizontal overhead position by way of a trolley type drive through a roller track system with counter weights. These doors are usually described as 'garage doors' due to the very similar mechanism they use. Unfortunately, this type of door needs additional excavation compared to the current barn door, which results in a higher development cost for the same door size section.

Roll up doors are made of small horizontal interlocking metal slats that are guided in a track. The configuration coils around an overhead drum which is housed at the head. Considering development, this alternative was more attractive as it only required the development of the frame size and reduced overhead clearance to accommodate the coil.

The opposing swing steel door, commonly referred to as a swing door, consists of two opposite door panels powered by a single drive system, which allows each panel to open in a different direction, counteracting forces produced by the pressure differential. This door also needed a minimal overhead development to be installed. It was also considered more robust for the application compared to the roll up door. Compared to the barn door it was a less expensive alternative, mainly due to the development cost involved.

Based on the previously explained reasoning, the swing door was selected to be the new ventilation and fire door for the Chuquicamata underground mine project.

As per the engineering review of the new swing doors, other aspects were considered as follows:

- Door engineering and fabrication: independent of airflow direction.

- Excavation (if necessary): minimal or no excavation required to install.

- Concrete foundation, mounting and door assembly: quick to install by trained workers, requires small foundation or leveller foot to fit frame, also equipped with jack lifts in upper frame to secure proper fitting.

- Start-up and maintenance: bushings instead of bearings, door leveller and bushing can operate submersed in water up to $0.5 \mathrm{~m}$. 
As a result of the engineering study, the swing door was considered to outperform the barn door in all of these aspects for the particular project requirements. The only clear limitation compared to the barn door was that the swing door could only handle up to a 1,250 Pa (5 in. wg) pressure drop, but based upon the updated engineering requirements for door pressure drop and the strategy of a series of multiple doors, this was not identified as an issue for implementation, other than at two particular locations.

Table 4 presents the swing door cost estimate, which considers supply, installation and maintenance for one year. Considering that the pressure drop requirement for this door is half of the barn door, the overall price reduction was not as significant, but still important in the range of $36 \%$.

Table 4 Ventilation and fire doors costs summary for swing type door

\begin{tabular}{llllll}
\hline Door type & $\begin{array}{l}\text { Door } \\
\text { number }\end{array}$ & $\begin{array}{l}\text { Supply } \\
\text { cost (USD) }\end{array}$ & $\begin{array}{l}\text { Installation } \\
\text { cost (USD) }\end{array}$ & $\begin{array}{l}\text { Maintenance } \\
\text { cost (USD) }\end{array}$ & $\begin{array}{l}\text { Total cost } \\
\text { (USD) }\end{array}$ \\
\hline Ventilation size A & 25 & 46,597 & 11,824 & 5,026 & $1,586,175$ \\
Ventilation size B & 12 & 60,576 & 15,371 & 5,026 & 971,676 \\
Fire size A & 6 & 55,917 & 11,824 & 5,026 & 436,602 \\
Fire size B & 4 & 72,692 & 15,371 & 5,026 & 372,356 \\
Total & 47 & $2,518,107$ & 612,480 & 236,222 & $3,366,809$ \\
\hline
\end{tabular}

\subsection{Door coverage problem solution}

With the updated information of the project plan, the design criteria, and the market solutions revision, the challenge was to identify the minimum set of different types of doors that covered all the requirements for the project at minimum cost.

The expected construction and installation cost considering automation and control for any of the proposed door types was less than the initial estimate. Generally, the less expensive the supply cost for the door, the less expensive the associated installation cost.

The definition of the types of doors required for each location could in theory be formulated as an optimisation coverage problem targeting minimum cost or a minimum number of door types. However at this stage, due to the rather small magnitude of the variables involved from the set of constraints that needed to be satisfied, a manual solution was easily achievable. Even if the solution could be identified as a local minimum, the manual sensitivity analysis performed around the proposed solution indicated that no better solution could be found.

As previously indicated and due to the current construction scope of work for 2017, only 21 doors were considered in this review. From those, 11 had already been installed and 10 remained to be installed. Out of the 11 doors in place, six needed to remain as barn doors because of high pressure drop requirements and because of their main function to act as an airlock to access underground facilities. These six doors are presented in Table 5 with the indication 'stays as barn door'. The other five installed doors indicated as 'remove barn for swing door' have to be changed out due to the current condition of the door and the need to have a swing door in its place. The specification of the remaining 10 doors resulted in the recommendation 'change to swing door'. 
Table 5 Ventilation and fire doors type change details (21)

\begin{tabular}{llllll}
\hline Door & $\begin{array}{l}\text { Pressure } \\
\text { drop } \\
\text { estimate } \\
\text { (Pa; in. wg) }\end{array}$ & Door type change & Door & $\begin{array}{l}\text { Pressure } \\
\text { drop } \\
\text { estimate } \\
\text { (Pa; in. wg) }\end{array}$ & Door type change \\
\hline PVE-101 & 2,$500 ; 10$ & Stays as barn door & PVE-120 & 1,$250 ; 5$ & Change to swing door \\
PVE-102 & 2,$500 ; 10$ & Stays as barn door & PVE-121 & 1,$250 ; 5$ & Change to swing door \\
PVE-105 & 1,$250 ; 5$ & Change to swing door & PVE-122 & 2,$500 ; 10$ & Stays as barn door \\
PVE-106 & 1,$250 ; 5$ & Change to swing door & PVE-123 & 2,$500 ; 10$ & Stays as barn door \\
PVE-113 & 1,$250 ; 5$ & Remove barn for swing door & PCl-105 & 1,$250 ; 5$ & Change to swing door \\
PVE-114 & 1,$250 ; 5$ & Remove barn for swing door & PCl-106 & 1,$250 ; 5$ & Change to swing door \\
PVE-115 & 1,$250 ; 5$ & Remove barn for swing door & PCl-107 & 1,$250 ; 5$ & Change to swing door \\
PVE-116 & 1,$250 ; 5$ & Remove barn for swing door & PCl-108 & 1,$250 ; 5$ & Change to swing door \\
PVE-117 & 1,$250 ; 5$ & Remove barn for swing door & PCl-122 & 1,$250 ; 5$ & Change to swing door \\
PVE-118 & 2,$500 ; 10$ & Stays as barn boor & PCl-123 & 1,$250 ; 5$ & Change to swing door \\
PVE-119 & 2,$500 ; 10$ & Stays as barn door & - & - & - \\
\hline
\end{tabular}

The new solution contains five different classifications across two door types, namely barn ventilation door size $A$, swing ventilation door sizes $A$ and $B$, and swing fire door sizes $A$ and $B$. Compared to the initial barn door exclusive solution, the new solution added a level of complexity in terms of the number of components of the ventilation system.

\section{$4 \quad$ Discussion and recommendation}

The new proposed solution has a number of differences compared to the previous phase of engineering. The main differences identified are:

- Safety.

- Supply, installation and maintenance cost.

- Spare parts and maintenance complexity.

In terms of safety, the new door solution is expected to be safer for both personnel and equipment, as it is not expected to be influenced by planned changes in the airflow direction.

Due to the reductions in pressure requirements resulting from the revised engineering, the swing door solution was less expensive than expected. An equivalent barn door solution with the new pressure requirement was not defined for comparison as it did not address the independency of airflow direction.

As presented in Table 4, when considering the 47 doors, the swing door solution is $36 \%$ less expensive than the initial barn door solution from the previous engineering phase. The detailed comparison presented in Table 6 shows a 10\% reduction in supply costs for ventilation swing doors and a $6 \%$ reduction for swing fire doors. The installation cost are reduced by $70 \%$ and maintenance costs by $50 \%$ for all door types. The overall cost reduction for the ventilation swing door was $36 \%$ and for the fire swing door $33 \%$.

Supply costs are not significantly impacted, as both types of door use very similar material and infrastructure: steel, controllers (programmable logic controllers), robust hydraulic systems and activation systems, among others. There is an important difference in terms of installation costs because the swing doors with up to a $1,250 \mathrm{~Pa}$ ( 5 in. wg) pressure drop rating do not require oversize foundations, anchorage drilling and additional 
rock excavation to mount the two hydraulic systems that the barn door needs. As components are fewer, smaller and simpler to inspect than with barn doors, the maintenance costs for a swing door are also significantly lower.

Table 6 Ventilation and fire doors cost savings for swing type door

\begin{tabular}{llllllll}
\hline \multirow{2}{*}{ Savings changing barn to swing door } & \multicolumn{3}{c}{ Supply cost } & \multicolumn{2}{l}{ Installation cost } & \multicolumn{2}{c}{ Maintenance cost } \\
\cline { 2 - 8 } & USD & $\%$ & USD & $\%$ & USD & $\%$ \\
\hline Ventilation size A & 5,177 & 10 & 27,589 & 70 & 5,026 & 50 \\
Ventilation size B & 6,731 & 10 & 35,866 & 70 & 5,026 & 50 \\
Fire size A & 3,675 & 6 & 27,589 & 70 & 5,026 & 50 \\
Fire size B & 4,778 & 6 & 35,866 & 70 & 5,026 & 50 \\
\hline
\end{tabular}

As mentioned previously, only six of the existing 11 ventilation doors cannot be changed. The remaining doors have the potential to be replaced by swing doors with the expectation to achieve the estimated savings, which are important and within 33 to $36 \%$ per unit.

In terms of spare parts and maintenance complexity, the new proposed door solution will be more complex to handle for the mine maintenance department, but the gains from the improved safety and cost savings were considered more valuable. As indicated in Table 6, the overall maintenance cost is expected to be lower with the new solution.

The recommendation for the project was to move forward with the implementation of the new doors. Additionally, it was also suggested to track installation and maintenance costs to validate the engineering estimates. Finally, the project will now assess, on a continuous basis, what is the most suitable door for the technical requirements, accounting for capital and operating budgets for the next phase of developments.

\section{Conclusions}

As part of the current phase of engineering and based on the updated information that the project has available, a revision of the location, number and type of ventilation and fire doors was developed by the Chuquicamata underground project team. The definition of the door types and their location had the potential to be formulated as the solution to a minimum cost coverage optimisation problem, but a manual solution could easily be identified avoiding the need for the linear optimisation approach. Different alternatives available in the market were considered for the type of door, but due to the active constraints, such as pressure drop and independency of airflow direction, the number of feasible solutions was reduced. The new solution demonstrated compliance with all the technical requirements and delivered substantial economic savings when compared to the initial solution of the previous phase of engineering. On a single door basis, the identified savings were in the range of 33 to $36 \%$ considering supply, installation and maintenance costs. As a result, it was recommended for implementation and is now part of the construction plan for the upcoming years.

\section{References}

McPherson, MJ 2009, Subsurface Ventilation and Environmental Engineering, Chapman \& Hall, London National Fire Protection Association 2016, NFPA 110: Standard for Emergency and Standby Power Systems, National Fire Protection Association, Quincy, viewed 24 July 2017, http://www.nfpa.org/codes-and-standards/all-codes-and-standards/list-of-codesand-standards/detail?code $=110$ 